\title{
New Technologies for Mobile Salesforce Management and CRM
}

\author{
Cameron Fisher \\ Massachusetts Institute of Technology, Cambridge, MA, USA \\ Email: cameronf@wharton.upenn.edu
}

How to cite this paper: Fisher, C. (2017) New Technologies for Mobile Salesforce Management and CRM. American Journal of Industrial and Business Management, 7 , 548-558.

https://doi.org/10.4236/ajibm.2017.74040

Received: February 10, 2017

Accepted: April 27, 2017

Published: April 30, 2017

Copyright $\odot 2017$ by author and Scientific Research Publishing Inc. This work is licensed under the Creative Commons Attribution International License (CC BY 4.0).

http://creativecommons.org/licenses/by/4.0/

\section{(c) (i) Open Access}

\begin{abstract}
As technology advances, the capabilities of the modern salesforce continue to evolve. By applying a modern CRM system, the ability to manage selling relationships is accelerating. This document describes a range of recent innovations that support a multichannel approach to building valuable customer connections.
\end{abstract}

\section{Keywords}

CRM, Cloud, Microsoft, Mobile, Salesforce, Sales Force Automation, Salesforce.com

\section{Introduction}

To modernize their sales teams, organizations are electing to retire their fleet of laptops and tablets. Why? Because salespeople in the field are transitioning to a more nimble approach.

The salesforce is better equipped to approach prospects, conduct a needs analysis and present a value proposition by using a mobile device via cloud-based solution platform. The Sales Representative can check a dashboard, retrieve a specialty e-brochure or confirm their next appointment-in the time it takes to stroll from their car, greet the receptionist... and ride up the elevator. At each customer touch point, the organization reinforces the value delivery while simplifying how customers interact and relate. To maximize the customer lifetime value (CLV), the Sales Representative strives to build a relationship and efficiently generate revenue from high potential prospects.

A better chance of winning maximum wallet share for total solutions is not derived from transactional selling of commoditized products. Instead, the relationship is nurtured-and enlists a network of stakeholders-to produce a consultative pitch. As the selling organization provides value, credibility increases 
and mutual trust grows, the prospect's organization will share more time and insights about opportunities. The prospect will not participate in a candid needs analysis unless trust is established. The return on sales effort investment can only grow if accurate needs are revealed by the prospect. The modernized salesforce automation guides the salesforce through the relationship with insights and context-sensitive actions.

The goal of this article is to explain recent technology advances and illustrate a conceptual model about the role of the mobile salesforce within the multichannel go-to-market framework. The salesforce has put aside laptops and tablets in favor of versatile devices that simplify connecting to people, processes and information.

\section{Literature Review}

The ongoing CRM process is well defined by Zablah, Bellenger, and Johnston [1] as "the development and leveraging of market intelligence for the purpose of building and maintaining a profit maximizing portfolio of customer relationships." Today's technology advances deliver more context-sensitive business support than ever before. Cloud based platforms require less upfront investment and simplify system administration and operations.

Customer relationship management (CRM) can include process [2] [3], strategy [4], capability [5] or tool [6]. Salesforce automation solutions are often key components of CRM systems [7] [8].

\section{Envision Modern Salesforce Management}

A range of empirical data was synthesized to produce a representative composite. Consider Figure 1 below for a hypothetical \$3 Billion annual revenue industrial marketing organization.

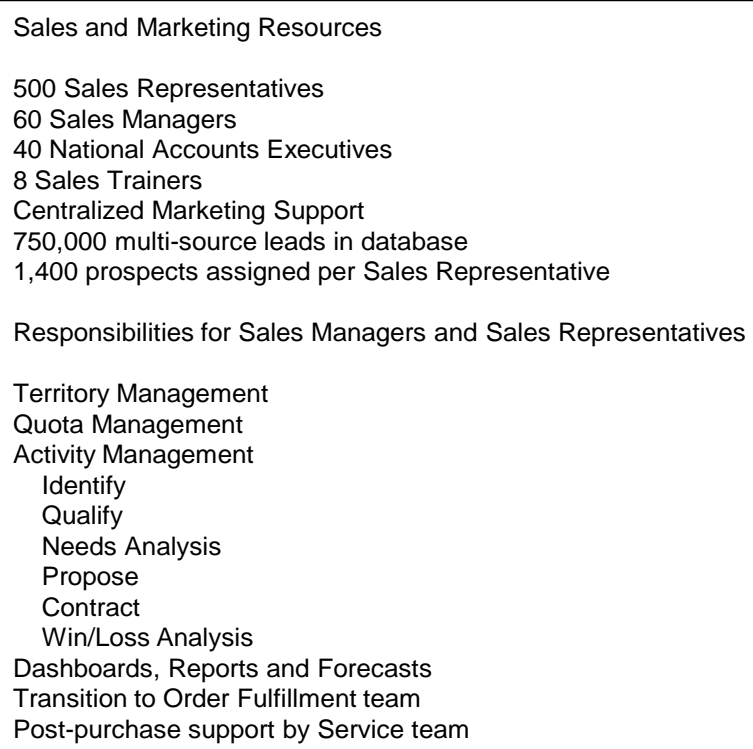

Figure 1. Derived from consultative engagements at anonymous organizations during introductions or replacements of modernized sales technologies during 20013-2016 [9]. 


\section{Example Implementing Salesforce Management Initiative}

To implement a new or modernized salesforce initiative, the major steps will typically include:

- Research Projected Scope, Benefits and Costs

- Define the Strategy, Process and Requirements

- Design the Solution and Platform

- Manage Organizational Change

- Pilot and Deploy

\section{Define Sales Process}

Organizations use CRM and SFA processes to collect critical data to enhance productivity, track goal attainment and execute a multi-channel contact strategy. The main channels that a growing organization can turn to include:

Brand management

Web impressions of prospects, customers, employees and partners

Outdoor marketing (billboard or vehicle signage)

Event marketing

Inside telesales

Outbound telemarketing

Direct salesforce

Campaigns

Call Centers

Store/Branch walk-in centers

Email

Web leads

Chat online

Social

Postal mail

Door-to-door

"The borders between physical and digital stores are breaking down ... Digital commerce is no longer an alternative sales channel. It's the business itself."

Wall Street Journal January 23, 2017, "Kroger CIO Pushes Grocer into Digital Era"

The business process flows diagrammed in Figure 2 show the roles and summarize the responsibilities typically involved in an organization's salesforce processes, CRM systems and digital marketing management.

Viewing account profiles, sales activity or recent purchasing history can be achieved on-the-go when Sales professionals call on their customers and prospects. Not only is the interface and functionality streamlined with advancing 




Figure 2. Actors and process flows for sales and marketing management.

software with increasingly precise personalization and predictive capabilities, the form factor innovation of today's devices continues to advance.

When equipping the sales channel to perform sales calls in the field, what is needed to help the sales teams succeed? Once prevalent, the Blackberry has been overtaken by Android, Windows and Apple devices. The laptop too, is increasingly superseded by business caliber smartphones. Should the individual employee be empowered to select their device of choice? No, because BYOD can introduce too much heterogeneity and loss of control. That makes it costly to support and difficult to prevent proprietary data leakage, especially if turnover of sales representatives is high. Since the latest devices can dock, their "3-in-1" approach is an effective alternative to the total ownership costs of a smartphone plus tablet plus PC.

The Sales Representative wants an effective, convenient device that affirms their persona as a credible professional. Headquarters has invested in sales methods and sales training. The executive sponsors must do their part for their mobilized salesforce.

Consider the following guided selling process integrated into the solution's user experience: 
Leads obtained from market research, prioritized

Cold calls and Phone calls to set appointments and build relations

Appointments to uncover needs

Meetings with prospect to explain/propose product, pricing and value

Contracts and signatures for terms, conditions, install dates, support

Follow-up for future upsell and completeness

In cases where turnover is high, the mobile interface's guided process helps newer representatives understand the sales process faster. If a process step is important (e.g. credit check), the sub-task can be designed as mandatory prior to advancing to a next step (e.g. presentation to prospect). Intelligent business rules enable relevant next best offers based on industry sector and customer profile. An inexperienced representative demonstrates greater confidence and is more productive when the solution provides the "next best action" for a prescribed selling process. The relevant guided process can be invoked by sales role, customer sector, and product line.

During recruiting and on boarding, the organization needs to make a positive impression. The candidate Sales Representative or Sales Manager is considering an important career move. "If I accept a new role and join this organization, will the culture/duties be a fulfilling experience?" Are the tools, policies and processes up-to-date and streamlined for team success? When on the road, is the connectivity meaningful and reliable to access a knowledgebase? What support mechanisms are in place, or does the new recruit fumble and quit?

Out in the field, the representative needs to think on his feet: What is the profile of this account? What solution offering is right for the prospect? What's the next best action? What policies, campaigns and exceptions apply? The salesforce automation platform can offer a guided selling process that delivers an easy-tofollow framework to convert leads into prospects and prospects into customers.

The buyer wonders: Is this person informative, relevant and up-to-date? If I buy from this representative, will it be a satisfying experience before, during and after the sale? Can I access a self-service portal for $24 \times 7$ requests and status tracking? When the organization bolsters the representative's success, the customer's confidence rises that the organization will support the customer's 360 degree success during and after the sales process.

To best serve the prospective buyer and organization's mission, the salesforce automation solution guides the stakeholders across a range of needs:

- Current position within prescribed sales process

- Next best action in the sales process

- Next best stop in a plotted GPS route for the day, week, month

- Next best offer in view of contact's relationship

- Next best offer for complementary products and services in view of buying history

- Proposals with legitimate SKUs, inventory levels and delivery schedules

- Proposals with specifications suited to a particular customer's industry and usage 
- Products and services configured with appropriate prices and discounts

- Contracting and electronic signatures to accelerate revenue recognition

- Goal tracking to display margin level, commissions, quota attainment, order status, gamification

- Win/Loss analysis

- Forecasts

- Consolidated roll-ups (team, region, line of business, consolidated organization)

\subsection{Design Solution Strategy and Platform}

If not already in place, the choice of a new or replacement architecture will depend on the needs of the organization. In some cases, the legacy data model will need to be revamped to reflect the modernized data attributes being collected and reported against. If the legacy system was fraught with customizations, or outdated attributes, re-thinking the new data architecture is mandatory. The leading suppliers of customer relationship management (CRM) platforms and salesforce automation solutions include:

Microsoft Dynamics 365

Salesforce.com

Oracle Customer Experience

Service Now

Sugar CRM

Microsoft Dynamics is gaining traction in the marketplace because of the seamless integration with Office 365, Outlook, Share point and Active Directory. The advances in Azure and the Cloud subscription model are now competitive to Salesforce.com and Oracle Sales Cloud. Microsoft and Salesforce.com both pursued a LinkedIn acquisition, and the race for mindshare and wallet continues to intensify among the leading vendors.

After deciding on the suitable software, processes and implementation approach, equipping the mobile users with a suitable device enables a mobile salesforce. The representative can connect to the prospect's monitor and this can avoid lugging around a laptop or tablet. Depending on the online platform, respective user roles and functionality needed, the license subscriptions are priced as the examples depict below for increasing levels of privileges and capabilities:

Approximate list price per online user per month by level of licensed capability:

Essential \$15

Basic $\$ 30$

Professional $\$ 50$

Enterprise $\quad \$ 90^{*}$ (centralized analytical users)

Hence, the annual licensing subscription costs for 500 users is $\$ 200,000$ per year. For 2000 users, the licensing subscription costs run approximately $\$ 800,000$ per year.

Cloud storage fees can also add to the operating costs of the overall platform and solution.

The requirement to read, write, append, delete, share and assign records will 
vary based on responsibilities and security settings per role. In recent months, the proportion of new installations are increasingly online and not on-premise. The rationale for the adoption of cloud platforms is attributable to several factors. One of the most compelling is ease of administration and ability to benefit from enhancements at periodic upgrades. Using production and non-production instances will also affect projected costs as the table illustrates below. For example:

Production Instance:

Non-production Instance (e.g. QA, Test)

Data storage

A modern device can be used by sales representatives on the go. Viewing account, contact, activity, opportunity, product information is vital to a mobile salesforce in the field. When working at the office or home, the dock and keyboard are available to provide a fully functional and less mobile experience.

\subsection{Example Matrix for Capturing Device Requirements}

To ensure the needs of the field users are captured, collect their preferences via survey, interviews or workshop. Use the attributes similar to Table 1 to select,

Table 1. Example mobile device requirements matrix.

\begin{tabular}{|c|c|c|c|c|c|}
\hline & Source & Required & Preferred & Optional & Exclude \\
\hline Requirement & (Trace-able name of employee) & & & & \\
\hline Detachable Keyboard & Juan Ho & & & & \\
\hline Dock to External Monitor & Pat Jones & & & & \\
\hline Easy Keystroke Input & etc. & & & & \\
\hline Apple iOS Operating System & & & & & \\
\hline Windows 10 Pro or Windows 10 Mobile & & & & & \\
\hline Android Operating System & & & & & \\
\hline Microsoft $\mathrm{O} 365$ compatible & & & & & \\
\hline Product Catalog capable & & & & & \\
\hline Document Repository Integration & & & & & \\
\hline Data Leakage Protection & & & & & \\
\hline Windows 10 Pro or Windows 10 Mobile & & & & & \\
\hline VPN and Security & & & & & \\
\hline Voice Recognition & & & & & \\
\hline USB Port External & & & & & \\
\hline Battery Life & & & & & \\
\hline Video/Photo Camera & & & & & \\
\hline Video Playback & & & & & \\
\hline Stylus & & & & & \\
\hline Charger Cable 3 Feet Minimum Length & & & & & \\
\hline Less than 2 lbs. Weight including Keyboard & & & & & \\
\hline Bluetooth & & & & & \\
\hline GPS Compatible & & & & & \\
\hline Durable Qwerty Keyboard & & & & & \\
\hline Water-resistant & & & & & \\
\hline Ruggedized Case & & & & & \\
\hline Enterprise Mobility Management & & & & & \\
\hline
\end{tabular}


negotiate and procure the entire fleet of devices and spare inventory. Prior to procuring, a trial period for a subset of the users can occur. More than one supplier can be evaluated during the trial(s).

The smartphone is at a turning point. The development of software and services on the phone is booming...expanding what the devices are capable of and making them increasingly indispensable.

Wall Street Journal January 16, 2017, "The Next Big Thing in Smartphones?"

\section{Pilot and Deploy}

- Review findings of expert research firms (e.g. Gartner, Forrester, etc.)

- Confer with expert implementation firms (e.g. Accenture, Slalom, etc.)

- procure trial devices

- image trial devices with software tools installed

- collect feedback via Survey

- analyze feedback collected

- Select Device Type Candidates for Primary Users (Sales Representatives and Sales Managers)

- Involve Program Management Office for Continual Communications and Organizational Change

- Plan for Hardware deployment to complement solution implementation

- Obtain pricing quotes and draft procurement strategy to equip salesforce and management

- Discounts, Quantities, Inventory Replenishment for lost or damaged devices

- Extrapolate trial users to program requirements for the entire salesforce

- Plan Enterprise Mobility Management (EMM) approach (e.g. Big Fix, MaaS 360, Microsoft Intune) for mobile device fleet management

- Manage Organization Change, including

- Communication Matrix

- Training Needs Analysis

- Leverage Microsoft "Learning Paths" native authored online tips

- User training aligned to solution and device roll out

- Deploy configured devices to global salesforce, sales managers and executives

With particular focus on the business user, HP has introduced a device offering that is well suited for a salesforce management solution as shown in Figure 3 .

Usability feedback during a pre-deployment trial can be obtained from Sales Representatives, Sales Managers, marketers and executives. Technical experts can also analyze and compare manufacturer's details for devices under consideration. Example specifications for the HP Elite X3 are shown in Figure 4.

Depending on the complexity of the organization, products, stakeholders and 

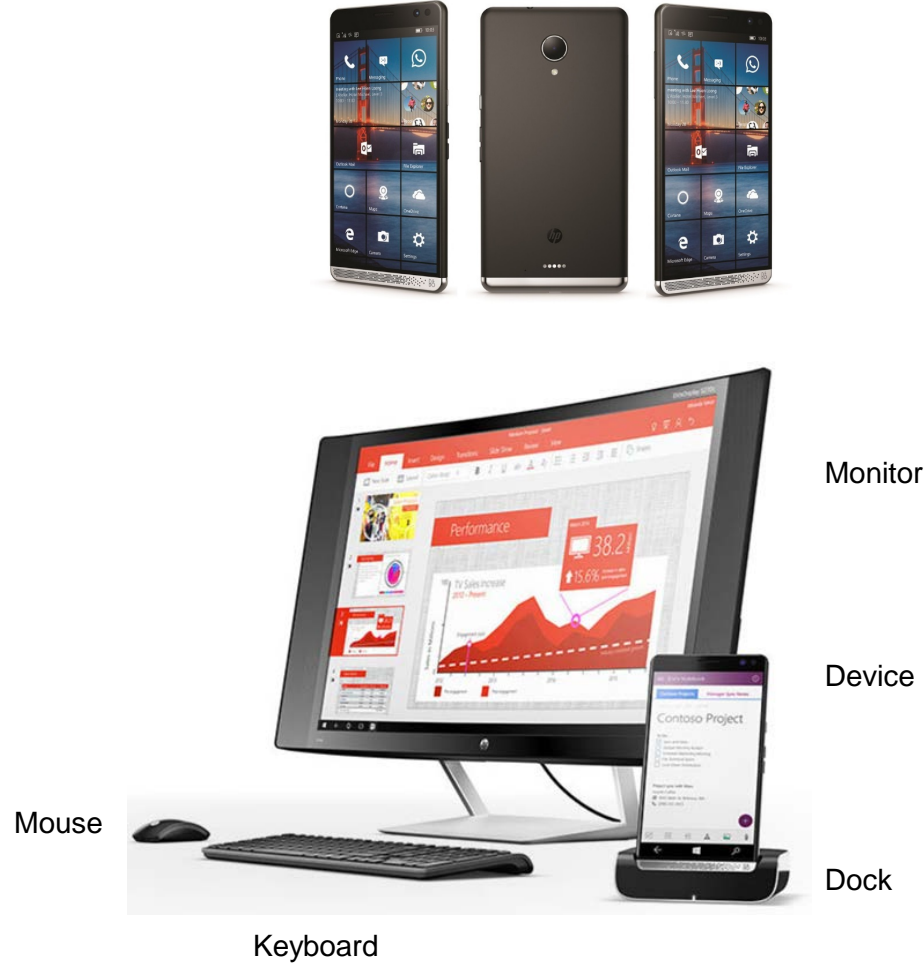

Figure 3. Mobile device configuration and peripherals.

\begin{tabular}{|c|c|}
\hline & Link to Example Specifications [10] \\
\hline Operating System & Windows 10 Mobile. \\
\hline Processor & Qualcomm ${ }^{\circledR}$ Snapdragon 820 (2.15 GHz, 4 cores). \\
\hline Display & $\begin{array}{l}\text { 5.96" diagonal WQHD AMOLED } 494 \text { PPI multitouch-enabled } \\
(2560 \times 1440) .\end{array}$ \\
\hline Battery life & $\begin{array}{l}\text { Up to: } 500 \text { hours standby time, } 33 \text { hours of talk time, } 14 \text { hours } \\
\text { web browsing time, } 13 \text { hours of video playback time [2]. }\end{array}$ \\
\hline Sensors & $\begin{array}{l}\text { Ambient light sensor + proximity combo; Accelerometer + gyro; } \\
\text { eCompass; Pressure; Hall effect; NFC; GPS. }\end{array}$ \\
\hline Integrated camera & $\begin{array}{l}16 \text { MP FHD rear-facing camera, } 8 \text { MP FHD front facing camera } \\
\text { and Iris camera. }\end{array}$ \\
\hline $\begin{array}{l}\text { Dimensions: } \\
\text { Width } \times \text { depth } \times \text { height }\end{array}$ & $\begin{array}{l}3.29 \times 0.31 \times 6.36 \text { in }(\mathrm{HP} \text { Elite } \times 3) ; 4.25 \times 3.74 \times 1.2 \text { in (HP Elite } \\
\times 3 \text { Desk Dock). }\end{array}$ \\
\hline Weight & Starting at $0.43 \mathrm{lb}$ (HP Elite $\times 3$ ). $0.99 \mathrm{lb}$ (HP Elite $\times 3$ Desk Dock); \\
\hline Security & $\begin{array}{l}\text { Elite } \times 3 \text { device has dual biometric authentication with iris recognition } \\
\text { and fingerprint reader, FIPS } 140-2 \text { cryptography; Qualcomm processor } \\
\text { includes Secure Boot, 128-bit key Unified Image Encryption, 256-bit key } \\
\text { full disk encryption, Anti roll back and fTPM } 2.0 \text { security; Windows } 10 \\
\text { includes } 128 \text { key Bitlocker encryption and enterprise grade VPN. }\end{array}$ \\
\hline
\end{tabular}

Figure 4. Example mobile device specifications for HP Elite x3.

selling methodology, a phased deployment often makes sense. This can expedite getting the solution into the hands of the salesforce and time to value. Refinements and adjustments can occur based on piloting and feedback checkpoints during introductory stabilization period and thereafter. 


\section{Conclusions}

The goal is for every touchpoint to be appropriate and consistent while reinforcing the brand with a minimum of customer effort. At every touchpoint, knowledge of customer needs and preferences improve. The lifetime value of a familiar customer generates more revenue and is less costly to identify, qualify, acquire and retain-compared to an unfamiliar customer. Customer intimacy enables the organization to deliver value with minimal customer exertion and efficient resourcing. Awareness of competitor offerings also improves when deeper customer relationships are built. The vulnerability to being commoditized or dis-intermediated (Uber-ized or Amazon-ized) is reduced.

For less mature organizations, the service function may continue as a separate silo. More mature organizations integrate processes to manage a 360 degree view of customer segmentation, satisfaction and lifetime value to the organization. The journey is ongoing and several components rely on a unified platform with common data structure. This is a primary reason to select a platform that can reliably build cross-channel coordination and cross functional operability. For example, cross selling among product lines, business entities and team representatives are usually pursued. Designing and deploying such enhancements will depend on prioritization as well as gaining stakeholder and sponsor buy-in as the organization and solution evolve.

The consistency and scalability of the sales process is enhanced when the solution platform and functionality align to requirements. Business analyst roles collaborate with business users and an agile solution/platform configuration team to design a solution and adoption approach. Tackling the integration of Sales and Service across Marketing, Finance, HR and Engineering is a difficult journey. Managing integrated contact centers and service operations to acquire and serve customers is a large undertaking. Moreover, integrations with ERP capabilities that include Finance, Manufacturing and HR require ongoing attention and refinement.

As the organization gains experience with the methodology and tools, refinements occur. The selling activities align better to the prescribed method, corporate mission and solution platform. The customer relationships can also better adapt in the event "how the customer likes to buy" changes. Sales operations planners derive knowledge from customers' feedback to update the selling processes that further strengthen relationships, guide better customer experiences, and build lasting and rewarding relationships.

\section{References}

[1] Zablah, A.R., Bellenger, D. and Johnston, W.J. (2004) An Evaluation of Divergent Perspectives on Customer Relationship Management: Towards a Common Understanding of an Emerging Phenomenon. Industrial Marketing Management, 33, 475489. https://doi.org/10.1016/j.indmarman.2004.01.006

[2] Day, G.S. and Van den Bulte, C. (2002) Superiority in Customer Relationship Management: Consequences for Competitive Advantage and Performance. The Wharton School, University of Pennsylvania. 
[3] Srivastava, R.K., Shervani, T.A. and Fahey, L. (1999) Marketing, Business Processes and Shareholder Value: An Organizationally Embedded View of Marketing Activities and the Discipline of Marketing. Journal of Marketing, 63, 168-179. https://doi.org/10.2307/1252110

[4] Voerhoef, P.C. and Donkers, B. (2001) Predicting Customer Potential Value, An Application in the Insurance Industry. ERIM Research in Management.

[5] Peppers, R. (2014) Measure the Value of Customer Experience Improvements.

[6] Shoemaker, M.E. (2001) A Framework for Examining IT-Enabled Market Relationships. Journal of Personal Selling \& Sales Management, 21.

[7] Morgan, A.J. and Inks, S.A. (2001) Technology and the Sales Force: Increasing Acceptance of Sales Force Automation. Industrial Marketing Management, 30, 463 472. https://doi.org/10.1016/S0019-8501(99)00115-7

[8] Pullig, C., Maxham, J.G. and Hair, J.F. (2002) Sales Force Automation Systems: An Exploratory Examination of Organizational Factors Associated with Effective Implementation and Sales Force Productivity. Journal of Business Research, 55, 401 415.

[9] (2013-2016) Derived Firsthand from Consultative Engagements at Anonymous Organizations, the Information Reflects Introductions or Replacements of Modernized Sales Technologies.

[10] http://store.hp.com/wcsstore/hpusstore/pdf/X9U42UT.pdf

Submit or recommend next manuscript to SCIRP and we will provide best service for you:

Accepting pre-submission inquiries through Email, Facebook, LinkedIn, Twitter, etc. A wide selection of journals (inclusive of 9 subjects, more than 200 journals)

Providing 24-hour high-quality service

User-friendly online submission system

Fair and swift peer-review system

Efficient typesetting and proofreading procedure

Display of the result of downloads and visits, as well as the number of cited articles

Maximum dissemination of your research work

Submit your manuscript at: http://papersubmission.scirp.org/

Or contact ajibm@scirp.org 